\title{
Influence of Walking with Talus Taping on the Ankle Dorsiflexion Passive Range of Motion
}

\author{
Min-Hyeok Kang, PT, MSc ${ }^{1)}$, Ji-Won Kim, PT, MSc ${ }^{1)}$, Moon-Hwan Kim, PT, MSc ${ }^{2)}$, \\ Tae-Jin Park, PhD ${ }^{3)}$, Ji-Hyuk Park, OT, PhD ${ }^{4}$, Jae-Seop Oh, PT, PhD ${ }^{5 *}$ \\ 1) Department of Rehabilitation Science, Graduate School, Inje University \\ 2) Department of Physical Therapy, Graduate School, Yonsei University \\ 3) Department of Sports Science, Pusan National University \\ 4) Department of Occupational Therapy, Yonsei University \\ 5) Department of Physical Therapy, College of Biomedical Science and Engineering, Inje University: \\ 607 Obang-dong, Gimhae-si, Gyeongsangnam-do 621-749, South Korea.
}

\begin{abstract}
Purpose] This study investigated the effects of walking with talus taping on the ankle dorsiflexion passive range of motion (DF PROM) in individuals with limited ankle DF PROM. [Subjects] Fifteen ankles with limited DF PROM were examined. [Methods] After rigid strapping tape was applied to the ankles from the talus to the calcaneus, progressing posteriorly and inferiorly, the subjects walked on a walkway for $10 \mathrm{~min}$. Using a goniometer, the ankle DF PROM was measured with the knee extended before and after walking with talus taping. The difference in ankle DF PROM between before and after walking with talus taping was analyzed using the paired t-test. [Results] The ankle DF PROM was significantly increased after walking with talus taping. [Conclusion] Our findings indicate that walking with talus taping is effective for increasing the ankle DF PROM in individuals with limited ankle DF PROM.
\end{abstract}

Key words: Ankle passive range of motion, Mobilization with movement, Talus taping

(This article was submitted Mar. 4, 2013, and was accepted Apr. 8, 2013)

\section{INTRODUCTION}

Walking from one place to another is a basic functional activity in daily living ${ }^{1,2}$. However, repeated abnormal walking patterns can induce foot and ankle injuries ${ }^{3,7)}$. Abnormal kinematics of the ankle during walking may increase the risk for chronic ankle instability and ankle sprain $^{3,4)}$.

Limited ankle dorsiflexion passive range of motion (DF PROM) with the knee extended can cause altered foot positions and compensatory foot movements leading to an abnormal walking pattern, which can result in ankle sprain and lower extremity overuse injuries ${ }^{5,6)}$. Willems et al. ${ }^{5)}$ suggested that limited ankle DF PROM tends to place the foot in the plantar flexion position, which contributes to ankle sprain related to ankle plantar flexion and inversion during sports activities. In addition, limited ankle DF PROM may increase stress in the tissues associated with lower extremity overuse injuries due to subtalar joint pronation and early heel off in compensatory foot motion during gait movement ${ }^{7)}$. In view of the importance of ankle DF PROM, clinicians are motivated to find an intervention to increase ankle DF PROM $5,8,9$ ).

The mobilization with movement (MWM) technique is an effective intervention for increasing the posterior glide

${ }^{*}$ To whom correspondence should be addressed.

E-mail: ysrehab@inje.ac.kr of the talus and ankle DF PROM ${ }^{10,11)}$. MWM for the ankle joint involves sustained anterior-to-posterior glide of the talus through passive manual force while the patient performs active ankle $\mathrm{DF}^{12)}$. For normal ankle DF PROM, sufficient posterior glide of the talus and adequate gastrocnemius and soleus muscle length are necessary ${ }^{2,13)}$. Anterior-to-posterior ankle joint mobilization improves arthrokinematic motion of the talus by increasing flexibility of the noncontractile tissues around the ankle joint ${ }^{14,}{ }^{15}$. Vicenzino et al. ${ }^{11)}$ showed that MWM for the ankle joint increased not only posterior glide of the talus but also ankle DF PROM in individuals with recurrent ankle sprain.

To acquire adequate motion of the talus, the application of tape to the talus is suggested ${ }^{13}$. Sahrmann ${ }^{13)}$ stated that application of tape to the talus posteriorly and inferiorly stabilizes the talus during tibial advancement movements. The stabilizing force from the tape may allow further tibial advancement over the foot as well as posterior glide of the talus. Considering that posterior glide of the talus is essential for sufficient ankle DF PROM ${ }^{2}$, improved glide of the talus during walking with talus taping may lead to an increase in ankle DF PROM.

Even though limited ankle DF PROM induces abnormal walking patterns associated with ankle and lower extremity overuse injuries ${ }^{6,7)}$, traditional interventions for increasing ankle DF PROM have not addressed the abnormal arthrokinematic motion of the talus during walking ${ }^{10,11,14)}$. To more efficiently increase ankle DF PROM, novel interventions combined with functional activity such as walking are 
required. Walking with talus taping is a suggested intervention for improving posterior glide of the talus and ankle DF PROM; however, no published reports have investigated the effects of walking with talus taping on ankle DF PROM. Based on previous results and clinical experience, we hypothesized that walking with talus taping would significantly increase ankle DF PROM, and this study was conducted to test this hypothesis.

\section{SUBJECTS AND METHODS}

Nine subjects with a mean age of $25.89 \pm 2.96$ years, mean weight of $65.69 \pm 13.85 \mathrm{~kg}$, and mean height of 169.61 $\pm 8.65 \mathrm{~cm}$ were recruited, and 15 ankles with limited ankle DF PROM (mean ankle DF PROM, $7.33 \pm 1.88^{\circ}$ ) were tested for this study. Subjects who had less than $10^{\circ}$ ankle DF PROM with the knee extended, unilaterally or bilaterally, and in whom the ankle DF PROM was greater with the knee flexed than with the knee extended were included in this study. Exclusion criteria included a history of surgery in a lower extremity, neurological diseases, and a lower extremity injury during the previous 6 months. Before participating, all subjects signed an informed consent form approved by the Inje University Faculty of Health Science Human Ethics Committee.

To measure the ankle DF PROM with the knee extended, subjects were placed in the prone position on a table with the knee extended and the tested ankle positioned over the edge of the table. An examiner applied force to the plantar surface of the foot until a firm resistance was encountered. The subtalar joint was maintained in a neutral position during the ankle DF PROM measurement. Another examiner confirmed the neutral subtalar position, and then measured the ankle DF ROM using a 14-inch stainless steel goniometer. The center of the fulcrum of the goniometer was placed over the lateral malleolus, the proximal arm of the goniometer was placed over the line from the fibular head to the lateral malleolus, and the distal arm was aligned parallel to the fifth metatarsal. With the knee extended in the prone position, the ankle DF PROM was measured three times before and after walking with talus taping, respectively, and the mean values of the three trials were used for data analysis.

After the ankle DF PROM was measured, the talus was taped. The tested ankle was placed on a chair, and the subject performed ankle DF in the weight-bearing position. Rigid tape (battlewin tape; Nichiban Co., Ltd., Tokyo, Japan) was applied from the talus to the calcaneus, passing below the medial and lateral malleoli. The subjects then walked around a walkway for $10 \mathrm{~min}$ with talus taping. After $10 \mathrm{~min}$, the rigid tape was removed, and the same examiner measured the ankle DF PROM of the subjects with the knee extended.

A paired t-test was used to assess the significance of the difference in ankle DF PROM between before and after walking with talus taping. Statistical analyses were performed with SPSS 17.0 for Windows (SPSS, Inc., Chicago, IL, USA), and an alpha level of 0.05 was considered statistically significant.
Table 1. Ankle dorsiflexion passive range of motion before and after walking with talus taping

\begin{tabular}{ccc}
\hline \multirow{2}{*}{ Variable } & \multicolumn{2}{c}{ Mean $\pm \mathrm{SD}\left(^{\circ}\right)$} \\
\cline { 2 - 3 } & $\begin{array}{c}\text { Before walking } \\
\text { with talus taping }\end{array}$ & $\begin{array}{c}\text { After walking } \\
\text { with talus taping }\end{array}$ \\
\hline Ankle DF PROM $\left(^{\circ}\right)$ & $7.33 \pm 1.88$ & $11.44 \pm 2.41^{*}$ \\
\hline
\end{tabular}

DF PROM, dorsiflexion passive range of motion. ${ }^{*} \mathrm{p}<0.05$

\section{RESULTS}

The measured ankle DF PROM was significantly greater after walking with talus taping than before walking with talus taping (Table 1).

\section{DISCUSSION}

This study demonstrated that walking with talus taping significantly increased the ankle DF PROM in individuals with limited ankle DF PROM.

A previous study found that posterior glide of the talus is an important factor for increasing ankle DF PROM ${ }^{14)}$. Green et al. ${ }^{14)}$ reported that individuals with ankle sprain acquired full pain-free ankle DF PROM after anterior-to-posterior ankle joint mobilization for 2 weeks. Posterior glide of the talus can also be accomplished by mobilization with move$\operatorname{ment}^{10,11)}$. The MWM technique uses manual force to produce sustained anterior-to-posterior glide of the talus during ankle DF, thereby improving the gliding motion of the talus and the ankle DF PROM. Walking with talus taping may produce a similar effect on the ankle joint because during the stance phase of the gait, tibial advancement over the foot acts as the ankle DF, and the posteriorly and inferiorly applied tape may aid posterior glide of the talus. During walking with talus taping, the posterior and inferior force applied to the talus by the tape may substitute for manual posterior glide of the talus in the MWM technique. Therefore, we infer that talus taping assists posterior glide of the talus during the stance phase of the gait and thus may increase ankle DF PROM. In addition, walking with talus taping was performed under weight-bearing conditions during the stance phase of the gait. Mulligan ${ }^{16)}$ stated that posterior glide of the talus is more effective with weight-bearing than under non-weight-bearing conditions because weight-bearing conditions reflect aspects of functional activities. In the current study, tibial advancement over the foot in the stance phase of the gait during walking with talus taping involved a weight-bearing condition, which may have contributed to the increased ankle DF PROM.

Previous interventions for increasing ankle DF PROM have overlooked the importance of correcting the abnormal walking pattern associated with limited ankle DF

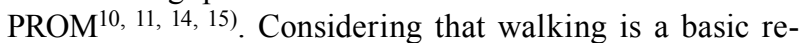
quirement for many activities ${ }^{1,2)}$, a combination of intervention for limited ankle DF PROM and walking activity is needed to improve the efficiency of the intervention. In contrast to joint mobilization or the MWM technique, walking with talus taping may correct abnormal arthrokinematic motion of the talus during walking, which increased the 
ankle DF PROM in our study. Furthermore, walking with talus taping has the benefits of time conservation and efficiency because it can be performed without a therapist's assistance. Thus, walking with talus taping is suggested as an efficient novel intervention for increasing ankle DF PROM in individuals with limited ankle DF PROM.

This study has some limitations. First, we did not measure the improvement in posterior glide of the talus after walking with talus taping. In view of the importance of posterior glide of the talus to ankle DF PROM, future studies should investigate the effects of walking with talus taping on posterior glide of the talus. Second, we did not measure how the increased ankle DF PROM after walking with talus taping influenced ankle motion during functional activities. The influence of talus taping on ankle kinematics during walking, running, and squatting should be demonstrated in future studies. Lastly, it is difficult to generalize our results to other populations because of the small sample size in the present study.

\section{REFERENCES}

1) Perry J, Burnfield JM: Gait Analysis: Normal and pathological function, 2nd ed. Thorofare: SLACK Inc, 2010.

2) Neumann DA: Kinesiology of the Musculoskeletal System: Foundations for rehabilitation, 2nd ed. St Louis: Mosby, 2010

3) Brown C: Foot clearance in walking and running in individuals with ankle instability. Am J Sports Med, 2011, 39: 1769-1776. [Medline] [CrossRef]

4) Willems T, Witvrouw E, Delbaere K, et al.: Relationship between gait biomechanics and inversion sprains: a prospective study of risk factors. Gait
Posture, 2005, 21: 379-387. [Medline] [CrossRef]

5) Willems TM, Witvrouw E, Delbaere K, et al.: Intrinsic risk factors for inversion ankle sprains in male subjects: a prospective study. Am J Sports Med, 2005, 33: 415-423. [Medline] [CrossRef]

6) Kibler WB, Goldberg C, Chandler TJ: Functional biomechanical deficits in running athletes with plantar fasciitis. Am J Sports Med, 1991, 19: 66-71. [Medline] [CrossRef]

7) Donatelli RA, Wooden MJ: Biomechanical orthotics. In: The Biomechanics of the Foot and Ankle, 2nd ed. Philadelphia: FA Davis Company, 1996.

8) Riddle DL, Pulisic M, Pidcoe P, et al.: Risk factors for Plantar fasciitis: a matched case-control study. J Bone Joint Surg Am, 2003, 85-A: 872-877. [Medline]

9) Kaufman KR, Brodine SK, Shaffer RA, et al.: The effect of foot structure and range of motion on musculoskeletal overuse injuries. Am J Sports Med, 1999, 27: 585-593. [Medline]

10) Collins N, Teys P, Vicenzino B: The initial effects of a Mulligan's mobilization with movement technique on dorsiflexion and pain in subacute ankle sprains. Man Ther, 2004, 9: 77-82. [Medline] [CrossRef]

11) Vicenzino $B$, Branjerdporn $M$, Teys $P$, et al.: Initial changes in posterior talar glide and dorsiflexion of the ankle after mobilization with movement in individuals with recurrent ankle sprain. J Orthop Sports Phys Ther, 2006, 36: 464-471. [Medline] [CrossRef]

12) Vicenzino B, Paungmali A, Teys P: Mulligan's mobilization-with-movement, positional faults and pain relief: current concepts from a critical review of literature. Man Ther, 2007, 12: 98-108. [Medline] [CrossRef]

13) Sahrmann SA: Movement System Impairment Syndromes of the Extremities, Cervical and Thoracic Spines. St. Louis: Mosby, 2010.

14) Green T, Refshauge K, Crosbie J, et al.: A randomized controlled trial of a passive accessory joint mobilization on acute ankle inversion sprains. Phys Ther, 2001, 81: 984-994. [Medline]

15) Hoch MC, Andreatta RD, Mullineaux DR, et al.: Two-week joint mobilization intervention improves self-reported function, range of motion, and dynamic balance in those with chronic ankle instability. J Orthop Res, 2012, 30: 1798-1804. [Medline] [CrossRef]

16) Mulligan BR: Manual Therapy "NAGS", "SNAGS", "MWM'S" Etc, 5th ed. Wellington: Plane View Services Ltd, 2004. 